\title{
长沙桃子湖湖水稳定同位素的变化及其影响因素”
}

\author{
华明权 ${ }^{1}$, 章新平 ${ }^{1,2 * *}$,姚天次 ${ }^{3}$, 罗紫东 ${ }^{1}$, 周 慧 $^{1}$, 饶志国 ${ }^{1}$, 贺新光 ${ }^{1,2}$ \\ ( 1 : 湖南师范大学资源与环境科学学院,长沙 410081) \\ ( 2 : 湖南师范大学地理空间大数据挖掘与应用湖南省重点实验室, 长沙 410081) \\ (3:中国科学院地理科学与资源研究所陆地水循环及地表过程重点实验室, 北京 100101)
}

\begin{abstract}
摘 要: 基于对长沙桃子湖湖水和降水中稳定同位素的监测数据, 分析了湖水中稳定同位素的变化特征及其与降水和蒸 发的关系, 旨在了解湿润气候条件下小型湖泊的湖水稳定同位素的变化规律, 揭示降水和蒸发对湖水稳定同位素变化的 具体影响. 在时间变化上, 湖水稳定同位素具有明显的季节变化, 湖水中 $\delta^{18} \mathrm{O}$ 的最大值出现在春季, 最小值出现在冬季; 湖水中过量氝的最大值出现在 5-6 月,最小值出现在 9-10 月. 在空间变化上,桃子湖不同深度和不同空间点上的湖水 中 $\delta^{18} \mathrm{O}$ 差异很小, 说明湖水基本处于均匀混合状态. 当 5 日累计降水量 $\geqslant 20.3 \mathrm{~mm}$ 时, 湖水中 $\delta^{18} \mathrm{O}$ 的变化与 5 日累计降 水量之间的负相关关系非常显著, 但与 5 日累计蒸发量之间呈弱正相关; 湖水中过量気的变化与 5 日累计降水量之间无 显著相关关系,但与 5 日累计蒸发量之间呈弱的相关性; 相比于平均湖水蒸发线,该降水段的蒸发线斜率和截距均有明显 增加. 当累计降水量 $<20.3 \mathrm{~mm}$ 时, 湖水中 $\delta^{18} \mathrm{O}$ 的变化与 5 日累计降水量之间的相关程度明显降低, 但与 5 日累计蒸发量 之间的相关程度则明显提高; 湖水中过量氛的变化与 5 日累计降水量以及与 5 日累计蒸发量之间的相关关系显著提高; 相比于平均湖水蒸发线,该组蒸发线的斜率和截距均有明显减小.
\end{abstract}

关键词: 稳定同位素; 过量気;桃子湖; 降水;蒸发;长沙

\section{Variation characteristics and influencing factors of the stable water isotopes in Lake Peach in Changsha City}

HUA Mingquan $^{1}$, ZHANG Xinping ${ }^{1,2 * *}$, YAO Tianci ${ }^{3}$, LUO Zidong ${ }^{1}$, ZHOU Hui ${ }^{1}$, RAO Zhiguo ${ }^{1} \&$ HE Xinguang $^{1,2}$

(1: College of Resources and Environmental Science, Hunan Normal University, Changsha 410081, P.R.China)

(2: Key Laboratory of Geospatial Big Data Mining and Application of Hunan Province, Hunan Normal University, Changsha 410081, P.R.China)

( 3: Key Laboratory of Water Cycle and Related Surface Processes, Institute of Geographic Sciences and Natural Resources Research, Chinese Academy of Sciences, Beijing 100101, P.R.China)

\footnotetext{
Abstract: Based on the monitoring data of stable isotopes in lake water and precipitation in Lake Peach in Changsha, the variation characteristics of stable isotopes in lake water in relation to precipitation and evaporation were analyzed. Our aims are to reveal the contributions of precipitation and evaporation to the variations in stable isotopes of the lake water and to understand the mechanism of stable isotopic variation in a small lake under humid climate conditions. In the temporal distributions, the seasonal variation of $\delta^{18} \mathrm{O}$ in lake was obvious, with the maximum $\delta^{18} \mathrm{O}$ in spring and the minimum in winter. The high values of $d$-excess in lake water were recorded in the period from May to June, and the low values in the period from September to October. In the spatial distributions, the differences of $\delta^{18} \mathrm{O}$ in lake among different depths and sampling points in Lake Peach were not significant, indicating that the lake was basically in a state of homogeneous mixing. The correlation between the variation of $\delta^{18} \mathrm{O}$ in lake and cumulated

* 国家自然科学基金项目 (41571021,41772373)、湖南省重点学科建设项目 (20160001) 和湖南省研究生科研创新项 目 (CX2017B229) 联合资助. 2018-01-30 收稿; 2018-03-24 收修改稿. 华明权 (1992 ), 男, 硕士; E-mail: hmqclh@163.com.

** 通信作者; E-mail: zxp@ hunnu.edu.cn.
} 
5-day precipitation amount $\left(P_{\mathrm{s}}\right)$ was significant, but the variation of $\delta{ }^{18} \mathrm{O}$ in lake was weakly correlated with the cumulated 5-day evaporation. There was no significant correlation between the variation of $d$-excess in lake and the $P_{\mathrm{s}}$, but the variation of $d$-excess was weakly correlated with the cumulated 5-day evaporation when the $P_{\mathrm{s}} \geqslant 20.3 \mathrm{~mm}$. Compared with the averaged Lake Evaporation Line ( LEL), the slope and intercept of the LEL increased significantly with the $P_{\mathrm{s}} \geqslant 20.3 \mathrm{~mm}$. Furthermore, when the $P_{\mathrm{s}}<20.3$ $\mathrm{mm}$, the correlation between the variation of $\delta^{18} \mathrm{O}$ in lake and the $P_{\mathrm{s}}$ was significantly decreased, but the correlation between $\delta^{18} \mathrm{O}$ in lake and the cumulated 5-day evaporation was significantly increased. Meanwhile, both the relationships between the variation of $d$ in lake and the $P_{\mathrm{s}}$ as well as the cumulated 5-day evaporation were significantly improved. On an average, the slope and intercept of the LEL were significantly reduced.

Keywords: Stable water isotopes; $d$-excess; Lake Peach; precipitation; evaporation; Changsha City

在水文研究中,利用湖水稳定同位素组成及其变化量可以估算水量各收支项,如湖泊蒸发量 ${ }^{[1]}$ 、渗漏量 和地下水入湖水量 ${ }^{[2]}$ 等难以利用传统方法监测得到的水量; 也可以揭示不同水体的转化补给关系 ${ }^{[3-4]}$; 在水 文气象学研究中, 基于大气水平衡方程,利用湖水稳定同位素组分可以计算湖水蒸发水汽对当地大气水汽 的贡献率 ${ }^{[5]}$; 在古气候古环境重建中, 湖相沉积物中稳定同位素变化对气温的演变具有指示作用 ${ }^{[6]}$. 这些同 位素技术的广泛应用很大程度上依赖于对湖水稳定同位素的观测以及对其变化机制的认识.

一般,湖水稳定同位素的变化受多重因子影响 ${ }^{[7-8]}$. Talbot 等 ${ }^{[9-10]}$ 认为,湖水稳定同位素的变化很大程度 上取决于湖泊系统的开放程度: 在一个开放的湖泊系统中, 伴随着地表径流的流人与流出, 湖水稳定同位素 的变化能反映区域降水中稳定同位素组成特征. 对于封闭湖泊, 湖泊的出水与补给分别来自蒸发与降水, 湖 水稳定同位素的变化反映了当地的降水蒸发比. Henderson 等 ${ }^{[11]}$ 对美国西部山区的湖泊群进行的调查显示, 湖水稳定同位素组分与降水稳定同位素组分的年雨量权重值密切相关. 徐敬争等 ${ }^{[12]}$ 在对太湖水稳定同位 素组成特征的研究中发现, 降水稳定同位素组分和水温并非是湖水稳定同位素变化的控制因素, 湖水稳定 同位素的变化主要受控于湖水蒸发量. 巩同梁等 ${ }^{[13]}$ 通过对羊卓雍湖流域湖水稳定同位素组分的调查研究 发现, 相对湿度是影响内陆湖水中 $\delta^{18} \mathrm{O}$ 平衡值的最主要因素, 而湖水温度的直接影响可以被忽略. Biggs 等 ${ }^{[14]}$ 认为通流系数 (湖水蒸发量占人湖水量比重) 是影响湖水稳定同位素富集程度的重要因素. Jones 等 ${ }^{[15]}$ 认为水通量是控制湖水中 $\delta^{18} 0$ 变化的关键因子. 可见,不同的区域, 控制湖水稳定同位素组成的因子不尽 相同.

长沙位于亚热带季风区, 大气环流形势复杂, 气候雨热同期, 是开展水循环过程中水稳定同位素迁移、 演变过程及机理研究的热点区域. 然而已有研究多关注降水 ${ }^{[16-17]}$, 对湖泊水体的报道还是空白. 此外, 在国 内,已有的大部分关于湖泊同位素变化的研究中,普遍是基于短时间内收集的数据, 且缺乏对包含降水同位 素等的系统性的取样监测. 这不利于对不同时间尺度下湖水稳定同位素变化细节的了解、亦不利于解读湖 水稳定同位素变异的规律. 本文基于对长沙市岳麓山下、湘江边的桃子湖为期两年半的湖水和降水中稳定 同位素的同步监测, 分析季风性湿润气候条件下湖水中稳定同位素组成特征, 旨在揭示湿润气候条件下湖 水稳定同位素的多时间尺度变化特征和空间分异规律, 量化降水和蒸发过程对湖水稳定同位素变化的影响 和识别两作用过程强弱互转的临界点. 研究结果将有助于了解季风区封闭湖泊的补给和蒸发状况, 同时可 为后期将要实施的湖水稳定同位素时间变化的模拟提供基础数据和理论支持.

\section{1 实验设计}

\section{1 实验站点概况}

取样点桃子湖 $\left(28^{\circ} 10^{\prime} 59.97^{\prime \prime} \sim 28^{\circ} 11^{\prime} 05.44^{\prime \prime} \mathrm{N}, 112^{\circ} 56^{\prime} 47.61^{\prime \prime} \sim 112^{\circ} 56^{\prime} 49.31^{\prime \prime} \mathrm{E}\right)$ 位于湖南长沙地区. 该湖 西倚岳麓山, 东邻湘江, 全湖水域面积 $0.08 \mathrm{~km}^{2}$, 总体呈现西部浅东部深的分布特点, 湖底标高 $27.5 \mathrm{~m}$, 平均 水深 $1.5 \mathrm{~m}$. 湖泊形状规则, 近似矩形, 属于人工生态景观湖泊. 2010 年的湖水提质改造工程截断了周边所有 注人湖中的生活污水, 湖泊无出人湖河流, 现湖水主要初始补给来源是大气降水, 存在一定程度的地下水补 给, 可视为 “封闭型”湖泊.

湖区所在的长沙地区位于我国的东部季风区, 夏季盛行西南和东南季风, 冬季盛行偏北风, 具有夏季高 温多雨、冬季温和少雨的气候特征. 根据中国气象科学数据共享服务网提供的气候统计资料, 研究区多年平 
均气温是 $17.2^{\circ} \mathrm{C}$, 多年平均降雨量为 $1361.6 \mathrm{~mm}$, 多年平均蒸发量为 $902.0 \mathrm{~mm}$.

\section{2 水样采集与测试}

2015 年 1 月 1 日至 2017 年 6 月 30 日每 $5 \mathrm{~d}$ 定点采集 1 次湖水水样, 整个观测期间, 在固定取样点共获 得 360 个湖水样品. 长期采样点设在水位较深 (约 $3 \mathrm{~m}$ ) 的桃子湖东部, 距岸边 $2.5 \mathrm{~m}$ (图 1 中红点). 采样时, 分别在湖面以下 $0.2 \mathrm{~m}$ 和 $1 \mathrm{~m}$ 深度处收集湖水样, 并同步记录水位高度. 除了在长期采样点的定点取样外, 自 2017 年 5 月 1 日至 9 月 16 日,每隔 5 10 d 利用橡皮船分别对湖内 8 个点(图 1 中 $\mathrm{A} \sim \mathrm{H}$ 点) 水面以下 0.2 $\mathrm{m}$ 和 $1 \mathrm{~m}$ 处的水体进行采样,一共人湖 16 次,在这 8 个补充取样点获得 256 个水样.

为了比较降水和湖水中稳定同位素组成的差异,在距离桃子湖 $1.2 \mathrm{~km}$ 的野外气象观测场进行了连续降 水观测, 取样频率为每日 2 次, 即每个降水日的 8:00 与 20:00, 观测期间共收集了 367 个降水样. 所有采集 的水样被装人 $30 \mathrm{ml}$ 聚乙烯样品瓶内, 编号、密封、低温保存并定期进行测试分析.

水样中氢氧稳定同位素的测定利用 Los Gatos Research (LGR) 公司研发的气一液两用型水稳定同位素 分析仪 (型号:912-0026-1000) 完成. 测得的氢氧稳定同位素的大小用相对于维也纳标准平均海洋水 (VSMOW) 稳定同位素组分的千分差值 $\delta$ 表示:

$$
\delta_{\text {sample }}=\left(R_{\text {sample }} / R_{\text {V-SMow }}-1\right) \times 1000 \%
$$

式中, $R_{\text {sample }}$ 和 $R_{\mathrm{V}-\mathrm{SMOW}}$ 分别代表水样中和标准平均海洋水中稳定同位素比率 $\left({ }^{2} \mathrm{H} /{ }^{1} \mathrm{H} ;{ }^{18} \mathrm{O} /{ }^{16} \mathrm{O}\right)$. $\delta^{18} \mathrm{O}$ 与 $\delta^{2} \mathrm{H}$ 的测试精度分别为 $\pm 0.2 \% 0$ 和 $\pm 0.6 \%$. 需要说明的是, 文中除了降水稳定同位素平均值是按相应时段内雨量 加权计算外,其他所有要素的平均值都是指时段内要素的算术平均值.

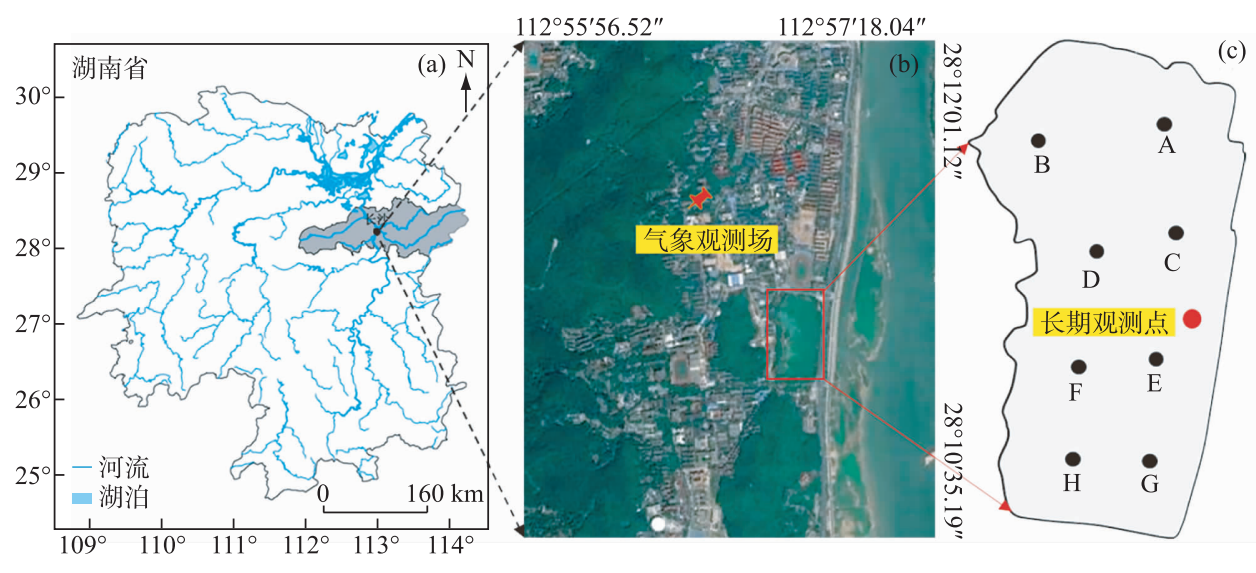

图 1 水样采集点位置

（点 $\mathrm{A} \sim \mathrm{H}$ 为 2017 年 5 月 1 日-9 月 16 日新增的湖泊水样监测点）

Fig.1 Location of research area and sampling sites

( Points A-H are the new lake observation points from May 1 to September 16, 2017)

一些相关的气象数据 (如气温、降水量 $(P)$ 等) 来源于气象观测场自动气象站的记录. 湖水蒸发量 $(E)$ 采用湖南省长沙市岳麓区气象站大型蒸发器(型号 E-601B) 日数据. 蒸发器 E-601B 的蒸发量非常接近于湖 泊、水库等中小水体的实际蒸发量, 能很好地说明这一地区的水面蒸发能力和湖水蒸发量的时间变化 ${ }^{[18-19]}$.

\section{2 结果与分析}

\section{1 湖水稳定同位素的时间变化特征}

取样期间桃子湖表层 $0.2 \mathrm{~m}$ 处湖水中 $\delta^{18} \mathrm{O}\left(\delta^{18} \mathrm{O}_{\mathrm{L}}\right)$ 、大气降水中的 $\delta^{18} \mathrm{O}\left(\delta^{18} \mathrm{O}_{\mathrm{P}}\right) 、 P 、 E$ 以及湖水水位的时 间变化见图 2. 观测期间, $\delta^{18} \mathrm{O}_{\mathrm{P}}$ 的变化介于 $-17.52 \% 0 \sim 6.73 \%$, 其降水量加权平均值为 $-6.54 \%$. $\delta^{18} \mathrm{O}_{\mathrm{P}}$ 的季节 分布表现为春季 $(-3.90 \% 0)>$ 冬季 $(-5.44 \% 0)>$ 夏季 $(-8.69 \% 0)>$ 秋季 $(-8.78 \% 0)$. 与 $\delta^{18} \mathrm{O}_{\mathrm{P}}$ 相比, $\delta^{18} \mathrm{O}_{\mathrm{L}}$ 的变化 幅度和离散度明显偏小, 稳定同位素组分明显偏高. 观测期间的 $\delta^{18} \mathrm{O}_{\mathrm{L}}$ 介于 $-5.56 \% 0 \sim-1.99 \%$ 之间,算术平均 
值为 $-3.86 \% . \delta^{18} \mathrm{O}_{\mathrm{L}}$ 的季节分布大致表现为春季 $(-3.40 \%)>$ 夏季 $(-3.78 \% 0)>$ 秋季 $(-4.19 \%)>$ 冬季 $(-4.21 \% 0)$.

降水过量氞 $\left(d_{\mathrm{P}}\right)$ 的变化在 $-8.82 \%$ 33.32\% 之间, 平均值约为 $14.38 \%$. $d_{\mathrm{P}}$ 的季节性变化表现为冬季高、 夏季低. 其中, 最高值多出现在 1 月, 最低值多出现在 7 月. 湖水中过量氞 $\left(d_{\mathrm{L}}\right)$ 的变化在 $-2.17 \% 0 \sim 10.13 \% 0$ 之 间, 平均值为 $4.36 \%$, 明显比降水过量気偏低. $d_{\mathrm{L}}$ 的峰值总是出现在 $d_{\mathrm{P}}$ 之后, 表现出一定的时滞性(图 2). 春、夏季由于降水量大, 蒸发相对较弱, 故 $d_{\mathrm{L}}$ 值较大, 最大值出现在 6 月; 同春、夏季相比, 秋季降水量较小而 蒸发量较大,故 $d_{\mathrm{L}}$ 值较小, 最小值多出现在 $9-10$ 月.

湖水稳定同位素与降水稳定同位素变化不一致的原因与湖水的补给和经历的蒸发强度有关. 一方面湖 水是降水、浅层地下水等多种水体的混合水体,对降水稳定同位素的变化具有平滑作用; 另一方面,湖水稳 定同位素的蒸发富集作用与降水对湖水稳定同位素的贫化作用存在时间变化上的差异.

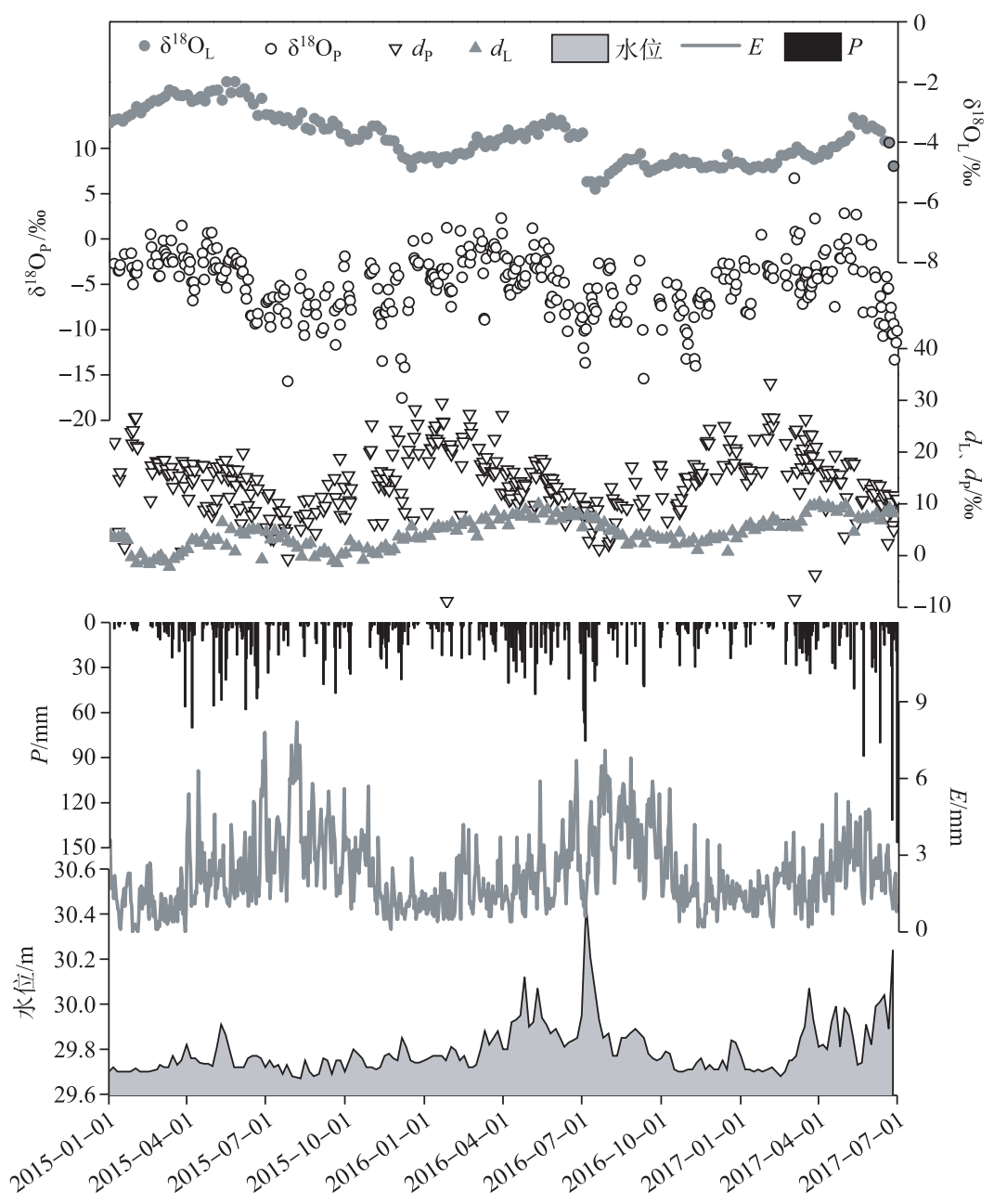

图 2 湖水和降水中 $\delta^{18} \mathrm{O}$ 、过量氞与降水量、蒸发量、湖水水位的时间变化

Fig. 2 Time series of $\delta^{18} \mathrm{O}$ and $d$-excess in lake water and precipitation, as well as precipitation amount, evaporation and the water level of lake

除了季节性的变化外, 湖水稳定同位素还存在年际变化上的差异. 统计表明, 2015 年的平均 $\delta^{18} \mathrm{O}_{\mathrm{L}}$ 为 $-3.16 \%$, 明显高于 2016 年的 $-4.38 \%$, 而 2017 年上半年平均 $\delta^{18} \mathrm{O}_{\mathrm{L}}$ 为 $-4.24 \%$, 与 2016 年同期接近. 湖水稳 
定同位素年际差异较大的可能原因与降水量的影响有关. 观测显示, 2014 年的秋、冬季节长沙地区降水量明 显偏少,仅为 $181.6 \mathrm{~mm}$, 仅占 2014 年年降水量的 $13.2 \%$. 在经历了长期的持续性蒸发之后, 2015 年年初的湖 水稳定同位素明显被富集. 与此同时, 受持续干旱的影响, 近地面大气水汽中的稳定同位素也明显被 富集 ${ }^{[20]}$.

\section{2 湖水稳定同位素的空间变化}

2.2.1 湖水稳定同位素的垂向变化 通常, 强烈的蒸发会使静水水体的表层富集重同位素,且湖水中稳定同 位素组分随水深逐渐减小. 为了解桃子湖水稳定同位素在垂直方向上的分布情况, 将取自水面以下 $0.2 \mathrm{~m}$ 和 $1 \mathrm{~m}$ 处各 180 个水样的 $\delta^{18} \mathrm{O}_{\mathrm{L}}$ 与 $d_{\mathrm{L}}$ 随时间的变化点绘于图 3. 可以看出, 2 个深度的湖水氧稳定同位素组分不 仅具有相似的变化趋势, 而且大小也十分相近. 统计结果表明, 2 个深度的 $\delta^{18} \mathrm{O}_{\mathrm{L}}$ 平均值均为 $-3.86 \%$, 它们的 均方根误差仅为 $0.22 \%$; 2 个深度的 $d_{\mathrm{L}}$ 平均值分别为 $4.33 \%$ 、 $4.18 \%$, 它们的均方根误差为 $1.83 \%$, 经检验, 两者的平均值不存在显著性差异.

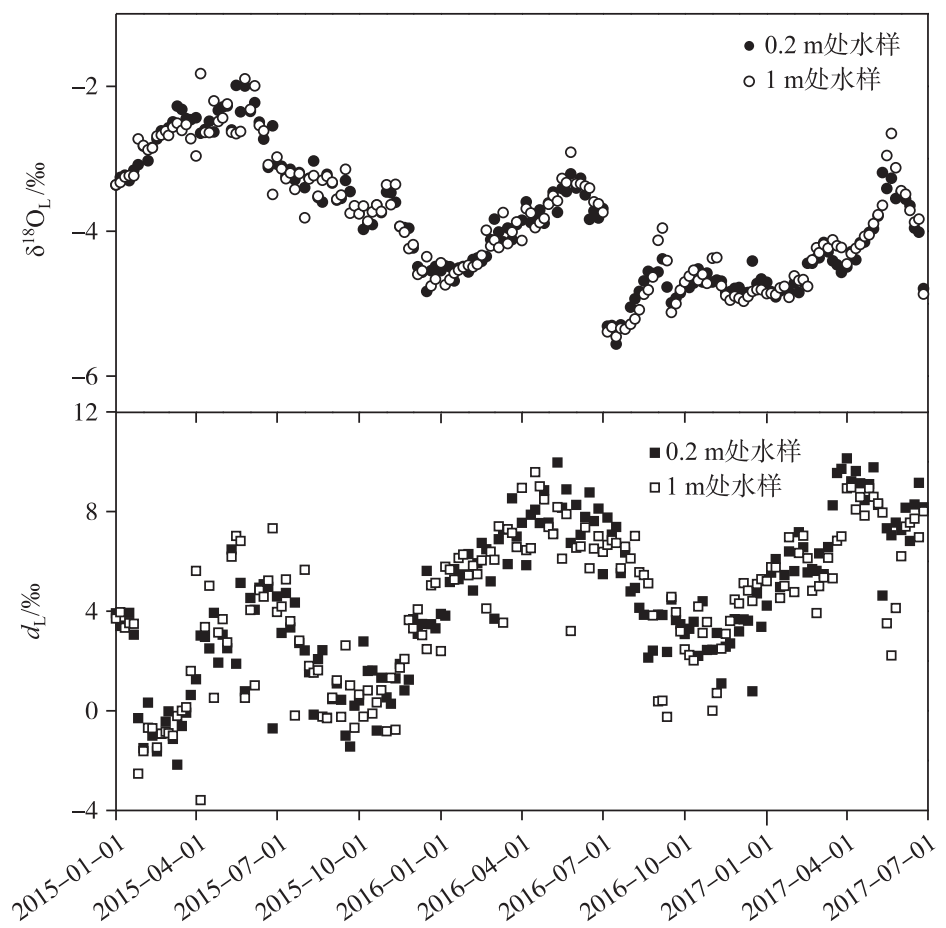

图 3 不同深度湖水中 $\delta^{18} \mathrm{O}$ 与过量気的变化

Fig.3 Variations of $\delta^{18} \mathrm{O}$ and $d$-excess with depth for the lake water

这个结果说明,对于桃子湖这样的小型浅水湖泊, 由于水体的垂直交换作用, 上下层之间的重同位素存 在一定程度的混合. 类似的结果在丽江拉市海 ${ }^{[21]}$ 、鄱阳湖 ${ }^{[22]}$ 等研究区域也有报道.

2.2.2 湖水稳定同位素水平方向上的变化 为了解湖水稳定同位素空间变化的特点, 基于不同点的水样数 据, 分别计算每个取样点两个深度的水稳定同位素算术平均值, 得到各采样点湖水 $\delta^{18} \mathrm{O}$ 随时间的变化 (图 4). 可以看出,各取样点的时间变化一致. 除了 2017 年 7 月 6 日外,其他时间点的水样中 $\delta^{18} O$ 在水平方向上 的差异均未超过 $0.20 \%$. 7 月 6 日的采样发生在 7 月 1 日的特大暴雨 ( 24 小时降水量为 $158.6 \mathrm{~mm}$ ) 之后. 受 大暴雨影响, 全湖各点 $\delta^{18} \mathrm{O}$ 急剧下降. 由于暴雨形成地表流集中汇人湖中, 导致该次全湖各点的水稳定同位 素差异偏大, 湖水中 $\delta^{18} \mathrm{O}$ 的变化在 $-8.18 \%$ - 7.76\% 之间.

湖水稳定同位素不存在显著的水平分布变化差异一方面是因为不同位置的湖水所经历的蒸发时间长 短基本一致; 另一方面是由于湖泊面积小, 且无人湖河流, 湖区周围因降水形成的地表产流以及浅层地下水 


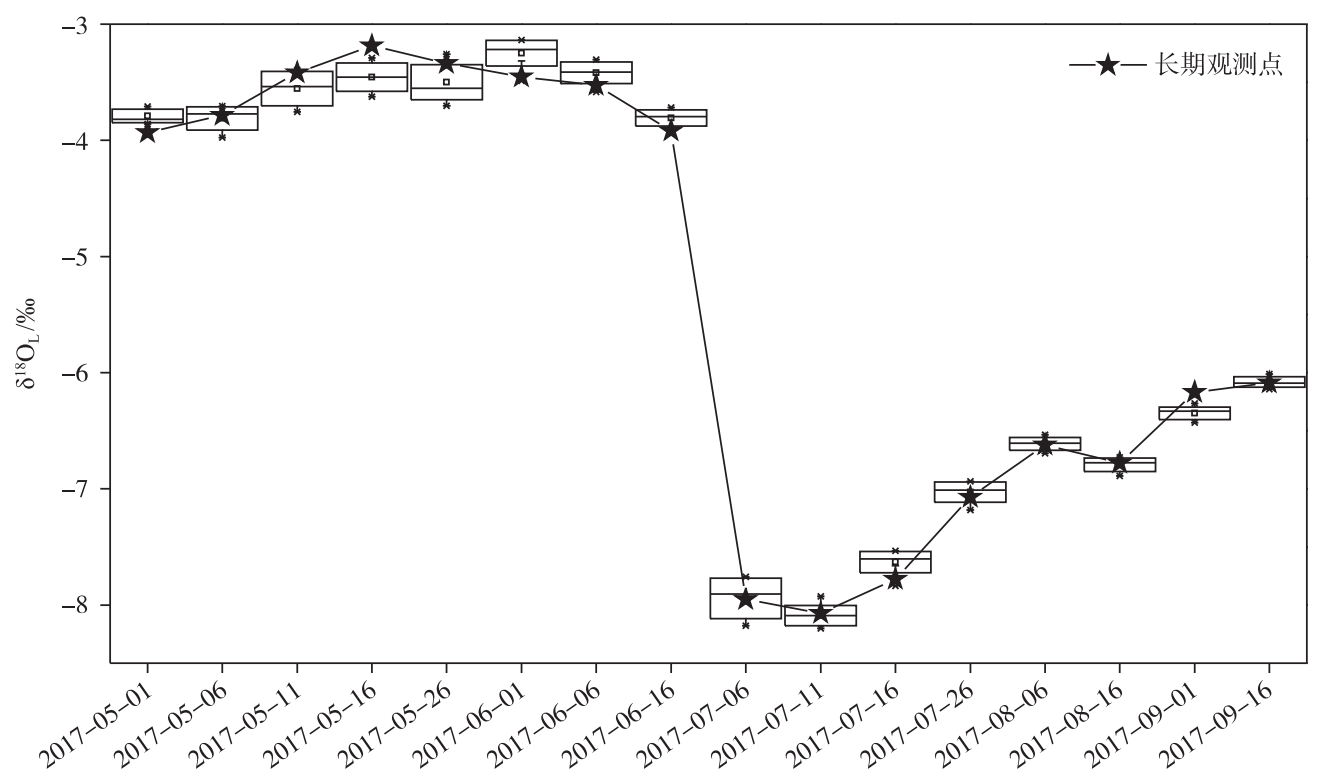

图 48 个采样点的湖水中 $\delta^{18} \mathrm{O}$ 随时间的箱式图

Fig.4 Box and whisker plots of $\delta^{18} \mathrm{O}$ in lake water of eight sampling sites

的稳定同位素组分与降水稳定同位素组分变化较相似.

综合不同深度和不同观测点的湖水稳定同位素的变化, 可以看出, 桃子湖的湖水稳定同位素的空间差 异小, 说明湖水基本处于混合的状态, 这一结果与浅水湖湖水一般可得到充分混合的观点 ${ }^{[23]}$ 相一致; 同时, 也佐证了在湖泊水平衡研究中,湖泊水稳定同位素混合均匀的假设是合理的 ${ }^{[24-25]}$.

\section{3 降水和蒸发对湖水稳定同位素的影响}

湖水稳定同位素组分的变化与湖水的蒸发和降水事件密切相关. 通常, 在持续无雨时, 湖水稳定同位素 组分呈上升的趋势; 受降水、尤其是大降水事件的影响,湖水稳定同位素组分呈减小的趋势. 由于湖水是按 5 日进行采集, 且湖水稳定同位素的丰度与降水和蒸发的累计作用有关, 因此, 降水中稳定同位素组分 $\delta^{18} O_{\mathrm{P}}$ 或 $\left(d_{\mathrm{P}}\right)$ 按 5 日计算雨量加权平均, 湖水中稳定同位素组分的改变量按相邻两次 $\delta^{18} \mathrm{O}_{\mathrm{L}}$ (或 $d_{\mathrm{L}}$ ) 值之差计算, 记 作 $\Delta \delta^{18} \mathrm{O}_{\mathrm{L}}\left(\right.$ 或 $\left.\Delta d_{\mathrm{L}}\right)$, 降水量和蒸发量则按 5 日累计值计算, 分别记为 $P_{\mathrm{s}}$ 和 $E_{\mathrm{s}}$.

\section{1 降水对湖水稳定同位素变化的影响}

大量的研究表明 ${ }^{[26-27]}$, 中低纬度沿海和季风气候区的降水中稳定同位素变化具有显著的“降水量效 应”. 分别将 5 日雨量加权平均 $\delta^{18} \mathrm{O}_{\mathrm{P}}$ 和 $\Delta \delta^{18} \mathrm{O}_{\mathrm{L}}$ 依 5 日累计降水量点绘在图 5. 根据图 5a, 研究区降水中稳定 同位素变化存在显著的降水量效应, 即 $\delta^{18} \mathrm{O}_{\mathrm{P}}$ 与 $P_{\mathrm{s}}$ 之间呈负相关关系：

$$
\delta^{18} \mathrm{O}_{\mathrm{P}}=-0.041 P_{\mathrm{s}}-3.972(r=-0.38, n=150)
$$

降水中 $\delta^{18} \mathrm{O}$ 与降水量之间的相关系数达到 -0.38 , 超过 0.001 的显著信度.

由于降水是湖水主要的和初始的补给来源, 湖水稳定同位素的变化继承了降水稳定同位素变化的降水 量效应. 又由于湖水稳定同位素明显比降水稳定同位素偏正, 因此,降水的影响总是使得湖水稳定同位素偏 负. 上述两个原因使得 $\Delta \delta^{18} \mathrm{O}_{\mathrm{L}}$ 与 $P_{\mathrm{s}}$ 之间的相关关系较 $\delta^{18} \mathrm{O}_{\mathrm{P}}$ 与 $P_{\mathrm{s}}$ 之间更加密切, 二者之间的相关系数达到 了 -0.64 ,远超 0.001 的信度, $\Delta \delta^{18} \mathrm{O}_{\mathrm{L}}$ 与 $P_{\mathrm{s}}$ 之间的线性拟合方程为:

$$
\Delta \delta^{18} \mathrm{O}_{\mathrm{L}}=-0.006 P_{\mathrm{s}}+0.122(r=-0.64, n=179)
$$

统计结果表明, 累计降水量越大, 湖水稳定同位素被贫化的程度也越大. 平均而言, $\Delta \delta^{18} \mathrm{O}_{\mathrm{L}}$ 随 $P_{\mathrm{s}}$ 的变化 率为 $-0.006 \% / \mathrm{mm}$, 小于降水稳定同位素 $-0.04 \% / \mathrm{mm}$ 的变化率. 这是抵消了湖水蒸发的富集作用、湖水的 

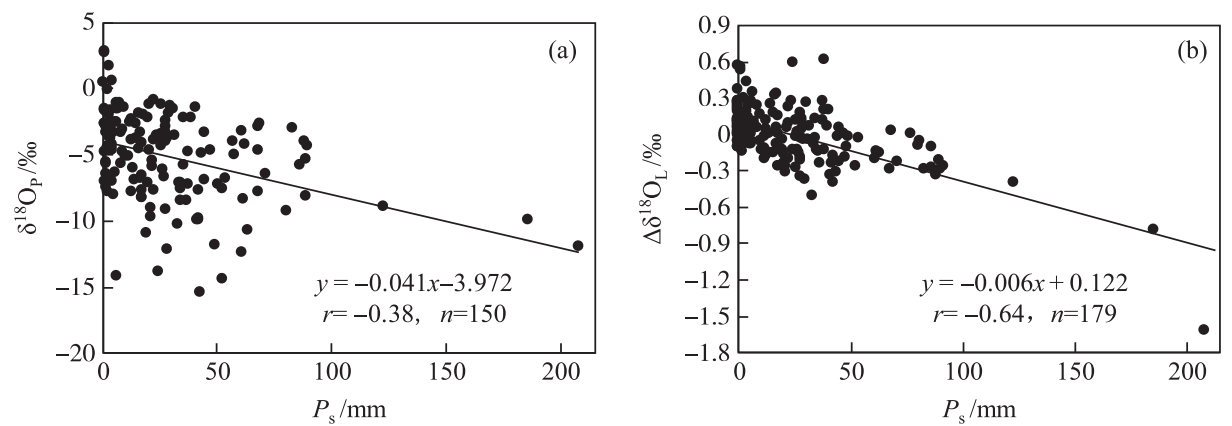

图 55 日加权平均 $\delta^{18} \mathrm{O}_{\mathrm{P}}(\mathrm{a})$ 和 5 日 $\Delta \delta^{18} \mathrm{O}_{\mathrm{L}}(\mathrm{b})$ 依累计降水量 $P_{\mathrm{s}}$ 的相关散布

Fig.5 Scatter plots of 5-day weighted average $\delta^{18} \mathrm{O}_{\mathrm{P}}(\mathrm{a})$ and $\Delta \delta^{18} \mathrm{O}_{\mathrm{L}}(\mathrm{b})$ versus cumulated 5-day precipitation amount respectively

累计平滑效应以及其他水源的补给作用 (例如地下水补给) 后的综合结果.

根据公式 (3), 当取 $P_{\mathrm{s}}=20.3 \mathrm{~mm}$ 时, $\Delta \delta^{18} \mathrm{O}_{\mathrm{L}}=0$, 表明 $P_{\mathrm{s}}$ 为 $20.3 \mathrm{~mm}$ 时, 降水对湖水稳定同位素的贫化 作用以及蒸发对湖水稳定同位素的富集作用大致抵消. 通过湖水稳定同位素组分的变化量 $\left(\Delta \delta^{18} \mathrm{O}_{\mathrm{L}}>\right.$ 或 $\left.<0\right)$ 能直观地揭示在不同降水量条件下湖水稳定同位素富集或贫化作用的影响因素. 因此, 为了定量分析不同 降水量对湖水稳定同位素组成的影响, 以 $20.3 \mathrm{~mm}$ 为界值, 将降水中和湖水中稳定同位素序列分为 2 个降水 区段: $P_{\mathrm{s}} \geqslant 20.3 \mathrm{~mm}$ 和 $P_{\mathrm{s}}<20.3 \mathrm{~mm}$, 讨论各组 $\delta^{18} \mathrm{O}_{\mathrm{P}}$ 和 $\Delta \delta^{18} \mathrm{O}_{\mathrm{L}}$ 分别与 $P_{\mathrm{s}}$ 之间的关系. 当 $P_{\mathrm{s}} \geqslant 20.3 \mathrm{~mm}$ 时, $\delta^{18} \mathrm{O}_{\mathrm{P}}$ 和 $\Delta \delta^{18} \mathrm{O}_{\mathrm{L}}$ 与 $P_{\mathrm{s}}$ 之间的相关关系为:

$$
\begin{aligned}
& \delta^{18} \mathrm{O}_{\mathrm{P}}=-0.027 P_{\mathrm{s}}-4.915(r=-0.25, n=80) \\
& \Delta \delta^{18} \mathrm{O}_{\mathrm{L}}=-0.006 P_{\mathrm{s}}+0.153(r=-0.65, n=79)
\end{aligned}
$$

当 $P_{\mathrm{s}}<20.3 \mathrm{~mm}$ 时, $\delta^{18} \mathrm{O}_{\mathrm{P}}$ 和 $\Delta \delta^{18} \mathrm{O}_{\mathrm{L}}$ 与 $P_{\mathrm{s}}$ 之间的相关关系为:

$$
\begin{aligned}
& \delta^{18} \mathrm{O}_{\mathrm{P}}=-0.151 P_{\mathrm{s}}-2.863(r=-0.31, n=70) \\
& \Delta \delta^{18} \mathrm{O}_{\mathrm{L}}=-0.007 P_{\mathrm{s}}+0.124(r=-0.27, n=100)
\end{aligned}
$$

在两类降水条件下, $\delta^{18} \mathrm{O}_{\mathrm{P}}$ 均与 $P_{\mathrm{s}}$ 存在大致相当的负相关关系. 尽管, 在两类降水事件下, $\Delta \delta^{18} \mathrm{O}_{\mathrm{L}}$ 与 $P_{\mathrm{s}}$ 之 间拟合线的斜率仅相差 0.001 , 但大降水事件条件下 $\Delta \delta^{18} \mathrm{O}_{\mathrm{L}}$ 与 $P_{\mathrm{s}}$ 之间相关系数达到 -0.65 , 显著高于小降水 事件下二者的相关系数 -0.27 , 一定程度说明了大降水事件对湖水稳定同位素的贫化作用更加明显. 例如, 在图 $2 \delta^{18} \mathrm{O}_{\mathrm{L}}$ 的逐日变化中, $\delta^{18} \mathrm{O}_{\mathrm{L}}$ 富集的过程所对应的降水量普遍偏小, 而 $\delta^{18} \mathrm{O}_{\mathrm{L}}$ 减小时所对应的降水量普 遍偏大. 取样期间, $\delta^{18} \mathrm{O}_{\mathrm{L}}$ 存在 3 次急剧的降低, 依次出现在 2015 年 6 月 21 日、2016 年 7 月 6 日和 2017 年 6 月 26 日, 对应的 5 日累计降水量分别为 $122.1 、 207.7$ 和 $185.5 \mathrm{~mm}$, 分别占当月降水量的 $44.5 \% 、 59.0 \%$ 和 $33.3 \%$.

类似地, 分别将 5 日加权平均 $d_{\mathrm{P}}$ 和 $\Delta d_{\mathrm{L}}$ 依 5 日累计降水量 $P_{\mathrm{s}}$ 点绘在图 6. 根据图 6a, 降水中过量氞与降 水量之间不存在显著的相关关系, 说明观测期间, 研究区降水的多少并不影响降水中过量氞的大小. 但由于 降水的平均过量氞 (14.38\% ) 明显大于湖水的平均过量氞 ( $4.36 \%$ ), 因此, 降水的补给增加了湖水中过量氞. 统计表明, $\Delta d_{\mathrm{L}}$ 与 $P_{\mathrm{s}}$ 之间具有显著的正相关关系:

$$
\Delta d_{\mathrm{L}}=0.014 P_{\mathrm{s}}-0.402(r=0.28, n=179)
$$

两者之间的相关系数达到了 0.28 , 超过 0.01 的信度. 这个结果表明, 整体而言, 随着累计降水量增加, 湖 水中过量気增大. 同样, 分降水区段考虑累计降水量对湖水过量気的影响:

$$
\begin{array}{ll}
\Delta d_{\mathrm{L}}=0.004 P_{\mathrm{s}}+0.259 & \left(P_{\mathrm{s}} \geqslant 20.3 \mathrm{~mm}, r=0.09, n=79\right) \\
\Delta d_{\mathrm{L}}=0.082 P_{\mathrm{s}}-0.875 & \left(P_{\mathrm{s}}<20.3 \mathrm{~mm}, r=0.33, n=100\right)
\end{array}
$$

当 $P_{\mathrm{s}} \geqslant 20.3 \mathrm{~mm}$ 时, 湖水的平均 $\Delta d_{\mathrm{L}}$ 为 $4.99 \%$, 比全时段湖水平均 $\Delta d_{\mathrm{L}}$ 大 $0.63 \%$. 但湖水中 $\Delta d_{\mathrm{L}}$ 与 $P_{\mathrm{s}}$ 之 间的相关系数仅为 0.09 , 二者之间的相关关系并不显著, 这个结果与降水 $\Delta d_{\mathrm{P}}$ 与 $P_{\mathrm{s}}$ 之间的关系一致; 当 $P_{\mathrm{s}}<$ 
$20.3 \mathrm{~mm}$ 时,湖水的平均 $\Delta d_{\mathrm{L}}$ 为 $3.90 \%$, 比全时段湖水平均 $\Delta d_{\mathrm{L}}$ 小 $0.46 \%$. 由于小降水条件下重同位素的强蒸 发富集效应导致散点图最左端的 $\Delta d_{\mathrm{L}}$ 下移, 从而加强了湖水 $\Delta d_{\mathrm{L}}$ 依 $P_{\mathrm{s}}$ 的线性关系, 也使得二者之间的正相关 系数达到 0.33 ,超过 0.001 信度.
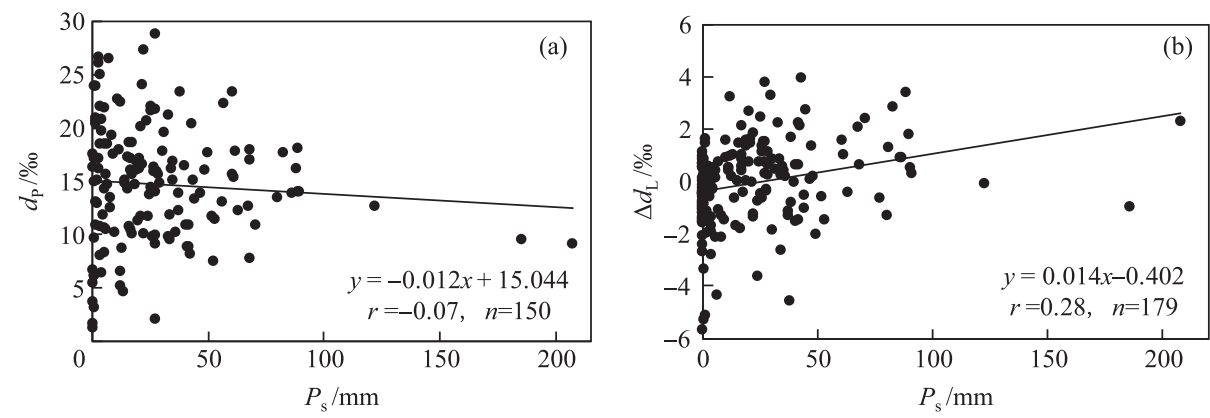

图 65 日加权平均 $d_{\mathrm{P}}(\mathrm{a})$ 和 5 日 $\Delta d_{\mathrm{L}}(\mathrm{b})$ 依累计降水量 $P_{\mathrm{s}}$ 的相关散布

Fig. 6 Scatter plots of 5-day weighted average $d_{\mathrm{P}}(\mathrm{a})$ and $\Delta d_{\mathrm{L}}($ b ) versus cumulated 5-day precipitation respectively

\section{2 蒸发对湖水稳定同位素变化的影响}

根据水循环中水稳定同位素的分馏原理,水稳定同位素的蒸发富集效应不仅导致剩余水中的重同位素 组分增大,还导致剩余水中的过量㲴减小. 在整个取样期间,连续 5 日无降水的事件 $\left(P_{\mathrm{s}}=0\right)$ 共出现了 33 次, 平均 5 日累计蒸发量 $E_{\mathrm{s}}$ 为 $14 \mathrm{~mm}$, 对应的 $\Delta \delta^{18} \mathrm{O}_{\mathrm{L}}$ 均大于 $0, \Delta d_{\mathrm{L}}$ 均小于 0 . 由于降水对湖水稳定同位素起 贫化作用,因此,蒸发对湖水稳定同位素变化的实际影响还包含了降水的因素.

分别将 $\Delta \delta^{18} \mathrm{O}_{\mathrm{L}}$ 和 $\Delta d_{\mathrm{L}}$ 依 5 日累计蒸发量 $E_{\mathrm{s}}$ 点绘在图 7. $\Delta \delta^{18} \mathrm{O}_{\mathrm{L}}$ 与 $E_{\mathrm{s}}$ 之间存在一定程度的正相关关系 (图 7a), 即:

$$
\Delta \delta^{18} \mathrm{O}_{\mathrm{L}}=0.007 E_{\mathrm{s}}-0.082(r=0.19, n=179)
$$

二者之间的相关系数为 0.19 , 超过了 0.05 的信度. 该统计结果表明, 累计蒸发量越大, 湖水稳定同位素 被富集的程度也越强. 平均而言, $\Delta \delta^{18} \mathrm{O}_{\mathrm{L}}$ 随 $E_{\mathrm{s}}$ 的变化率为 $0.007 \% \mathrm{o} / \mathrm{mm}$, 与 $\Delta \delta^{18} \mathrm{O}_{\mathrm{L}}$ 随 $P_{\mathrm{s}}$ 的变化率 $-0.006 \%$ / $\mathrm{mm}$ 相当, 说明桃子湖的湖水稳定同位素大致维持平衡.
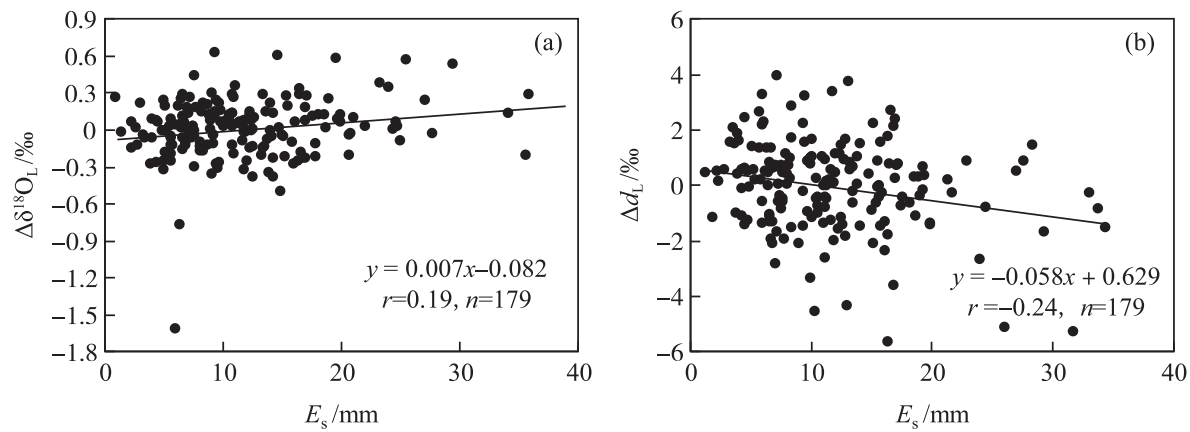

图 7 湖水中 5 日 $\Delta \delta^{18} \mathrm{O}_{\mathrm{L}}(\mathrm{a})$ 和 $\Delta d_{\mathrm{L}}(\mathrm{b})$ 依 5 日累计蒸发量 $E_{\mathrm{s}}$ 的相关散布

Fig.7 Scatter plots of 5-day $\Delta \delta^{18} \mathrm{O}_{\mathrm{L}}($ a $)$ and $\Delta d_{\mathrm{L}}$ ( b) versus cumulated 5-day evaporation $E_{\mathrm{s}}$ respectively

在大降水事件下,湖水稳定同位素的“降水量效应”极可能会掩盖湖水的蒸发富集作用. 因此,同样分降 水区段考虑累计蒸发量对 $\delta^{18} \mathrm{O}_{\mathrm{L}}$ 变化的影响, 不同降水区段下 $\Delta \delta^{18} \mathrm{O}_{\mathrm{L}}$ 与 $E_{\mathrm{s}}$ 之间的相关关系分别为:

$$
\begin{array}{ll}
\Delta \delta^{18} \mathrm{O}_{\mathrm{L}}=0.006 E_{\mathrm{s}}-0.178 & \left(P_{\mathrm{s}} \geqslant 20.3 \mathrm{~mm}, r=0.12, n=79\right) \\
\Delta \delta^{18} \mathrm{O}_{\mathrm{L}}=0.007 E_{\mathrm{s}}+0.006 & \left(P_{\mathrm{s}}<20.3 \mathrm{~mm}, r=0.31, n=100\right)
\end{array}
$$

当 $P_{\mathrm{s}} \geqslant 20.3 \mathrm{~mm}$ 时, $\Delta \delta^{18} \mathrm{O}_{\mathrm{L}}$ 与 $E_{\mathrm{s}}$ 之间的相关系数仅为 0.12 , 二者呈弱显著相关. 这个结果说明, 在强降 
水的作用下, 水体的蒸发富集作用被弱化; 当 $P_{\mathrm{s}}<20.3 \mathrm{~mm}$ 时, $\Delta \delta^{18} \mathrm{O}_{\mathrm{L}}$ 与 $E_{\mathrm{s}}$ 之间的相关系数达到 0.31 , 超过 0.005 的信度.

$\Delta d_{\mathrm{L}}$ 与 $E_{\mathrm{s}}$ 之间存在一定程度的负相关关系 (图 7b) , 即:

$$
\Delta d_{\mathrm{L}}=-0.058 E_{\mathrm{s}}+0.629(r=-0.24, n=179)
$$

二者之间的相关系数为 -0.24 , 超过了 0.01 的信度. 该结果表明, 累计蒸发量越大, 湖水中过量氝减小的 程度也越强. 平均而言, $\Delta d_{\mathrm{L}}$ 随 $E_{\mathrm{s}}$ 的变化率为 $-0.058 \% / \mathrm{mm}$, 大于 $\Delta d_{\mathrm{L}}$ 随 $P_{\mathrm{s}}$ 的变化率. 分降水区段考虑 $E_{\mathrm{s}}$ 对湖 水 $\Delta d_{\mathrm{L}}$ 的影响, $\Delta d_{\mathrm{L}}$ 与 $E_{\mathrm{s}}$ 之间相关关系为:

$$
\begin{aligned}
& \Delta d_{\mathrm{L}}=-0.069 E_{\mathrm{s}}+1.251\left(P_{\mathrm{s}} \geqslant 20.3 \mathrm{~mm}, r=-0.22, n=79\right) \\
& \Delta d_{\mathrm{L}}=-0.050 E_{\mathrm{s}}+0.123\left(P_{\mathrm{s}}<20.3 \mathrm{~mm}, r=-0.25, n=100\right)
\end{aligned}
$$
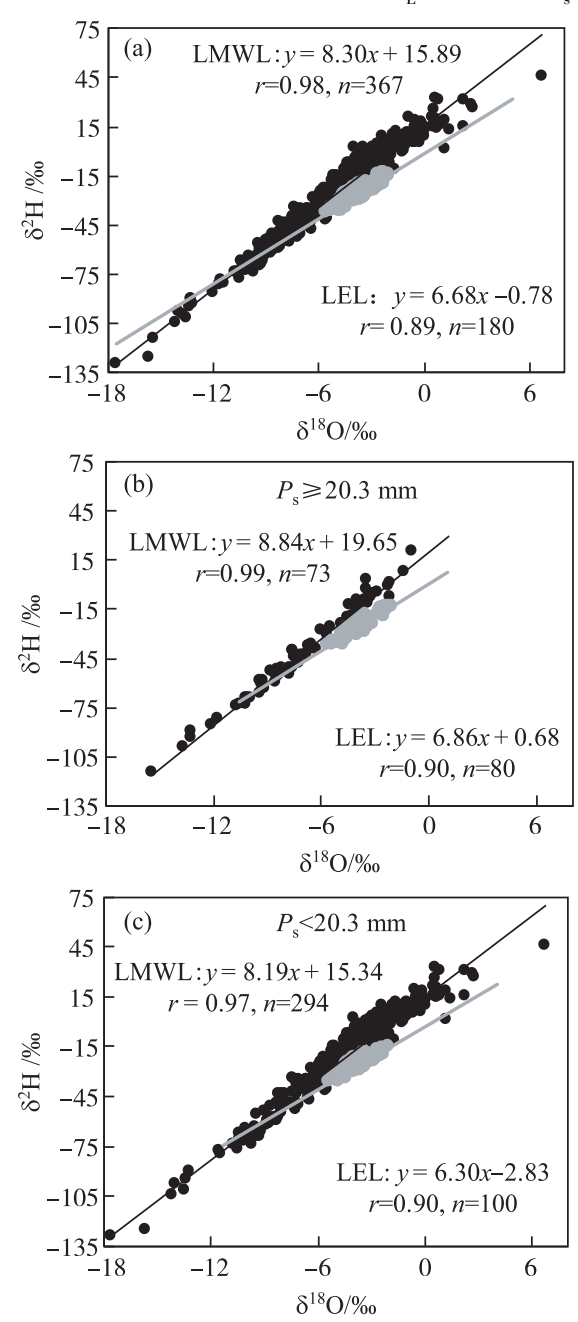

图 8 研究区的大气水线和湖水蒸发线

Fig. 8 Meteoric water lines and lake evaporation lines in Lake Peach

当 $P_{\mathrm{s}} \geqslant 20.3 \mathrm{~mm}$ 时, $\Delta d_{\mathrm{L}}$ 与 $E_{\mathrm{s}}$ 之间的相关系数为 -0.22 , 二者之间呈弱相关性. 当 $P_{\mathrm{s}}<20.3 \mathrm{~mm}$ 时, 湖水 $\Delta d_{\mathrm{L}}$ 与 $E_{\mathrm{s}}$ 之间 的相关系数为 -0.25 ,超过 0.02 的信度, 说明蒸发使湖水过量 氞的减小作用在小降水条件下更显著.

\section{3 湖水蒸发线}

Craig ${ }^{[28]}$ 将大气降水中 $\delta^{18} \mathrm{O}$ 与 $\delta^{2} \mathrm{H}$ 之间的线性关系定义 为大气水线,并给出了全球降水线 $(\mathrm{GMWL})$ :

$$
\delta^{2} \mathrm{H}=8 \delta^{18} \mathrm{O}+10
$$

由于各地区影响降水稳定同位素组分的因素不同,大气 水线具有明显的区域性,不同地区的大气水线被称为当地大 气降水线 ( LMWL). 参照大气水线 (MWL) 的定义, Gibson 等 ${ }^{[29]}$ 将被蒸发水体中 $\delta^{18} \mathrm{O}$ 和 $\delta^{2} \mathrm{H}$ 的线性关系定义为蒸发 线, 不同地区的蒸发线被定义为当地蒸发线 (LEL). 通过比 较不同大气水线以及不同蒸发线可以揭示不同区域的水文 气象状况 ${ }^{[30]}$, 区分不同水体补给来源 ${ }^{[31]}$ 和不同气象要素的 贡献 ${ }^{[32]}$.

根据研究期间所有实测的日平均降水 $\delta^{2} \mathrm{H}$ 和 $\delta^{18} \mathrm{O}$ 计算 的 LMWL 以及根据所有实测的湖水 $\delta^{2} \mathrm{H}$ 和 $\delta^{18} \mathrm{O}$ 计算的 LEL (图 8a) 分别为:

$$
\begin{gathered}
\delta^{2} \mathrm{H}=8.30 \delta^{18} \mathrm{O}+15.89(\text { LMWL }, r=0.98 ; n=367) \\
\delta^{2} \mathrm{H}=6.68 \delta^{18} \mathrm{O}-0.78(\mathrm{LEL}, r=0.89 ; n=180)
\end{gathered}
$$

该 LMWL 很好地再现了典型季风区降水中 $\delta^{2} \mathrm{H}$ 和 $\delta^{18} \mathrm{O}$ 之间的关系, 反映了研究区降水的水汽具有暖湿、对流性强 的气候特征,大于 8.0 的 LMWL 斜率和 0.98 的相关系数, 说 明雨滴降落中受到的蒸发富集作用较弱 ${ }^{[33-34]}$. LEL 明显小于 8.0 的斜率、小于 0 的截距以及相对较小的相关系数, 说明水 体经历了较强的蒸发.

分降水区段考虑 LMWL 与 LEL 的差别, 当 $P_{\mathrm{s}} \geqslant 20.3$ $\mathrm{mm}$ 时,

$$
\begin{gathered}
\delta^{2} \mathrm{H}=8.84 \delta^{18} \mathrm{O}+19.65(\mathrm{LMWL}, r=0.99, n=73) \\
\delta^{2} \mathrm{H}=6.86 \delta^{18} \mathrm{O}+0.68(\mathrm{LEL}, r=0.90, n=80)
\end{gathered}
$$

当 $P_{\mathrm{s}}<20.3 \mathrm{~mm}$ 时,

$$
\begin{gathered}
\delta^{2} \mathrm{H}=8.19 \delta^{18} \mathrm{O}+15.34(\text { LMWL }, r=0.97, n=294) \\
\delta^{2} \mathrm{H}=6.30 \delta^{18} \mathrm{O}-2.83(\mathrm{LEL}, r=0.90, n=100)
\end{gathered}
$$

在强降水段, 非常高的 LMWL 斜率和 0.99 的相关系数说明降落雨滴未明显受到蒸发富集的影响. 相比 
于式 (13), LEL 的斜率和截距均有明显增加. 这一方面是由于降水的影响, 另一方面也是由于平均蒸发富集 程度的减弱导致了 LEL 斜率和截距的偏大; 在弱降水段, 除了受 LMWL 的斜率和截距减小的影响之外, 弱降 水时平均蒸发富集程度的加强也是导致 LEL 斜率和截距减小的重要原因.

\section{4 结论与讨论}

基于对桃子湖为期两年半的湖水和降水中稳定同位素监测数据, 分析了典型季风湿润气候条件下小型 湖泊的湖水中稳定同位素的变化特征、湖水稳定同位素变化与降水和蒸发的关系、湖水蒸发线与大气水线 的关系,得到了一些有意义的结果 (表 1 ).

在时间变化上,桃子湖湖水稳定同位素具有明显的季节和年际变化特征, 春季的 $\delta^{18} \mathrm{O}_{\mathrm{L}}$ 最大, 冬季的 $\delta^{18} \mathrm{O}_{\mathrm{L}}$ 最小, $d_{\mathrm{L}}$ 的最大值多出现在 5-6 月, 最小值多出现在 9- 10 月; 2015 年的 $\delta{ }^{18} \mathrm{O}_{\mathrm{L}}$ 高于 2016 年和 2017 年, $d_{\mathrm{L}}$ 则正好相反. 与降水中稳定同位素相比, $\delta^{18} \mathrm{O}_{\mathrm{L}}$ 明显偏大, $d_{\mathrm{L}}$ 则明显偏小; 湖水稳定同位素的离散程度小 于降水, 且两者表现出不一样的季节变化, $\delta^{18} \mathrm{O}_{\mathrm{P}}$ 的季节分布为春冬季高、夏秋季低. 在空间变化上, 桃子湖不 同深度和不同空间点上的湖水稳定同位素差异很小,说明湖水基本处于均匀混合状态.

表 1 桃子湖湖水和大气降水中稳定同位素统计

Tab.1 Statistics list of stable water isotope in precipitation and water of Lake Peach

\begin{tabular}{lcccc}
\hline 项目 & 类别 & 合计 & $P_{\mathrm{s}} \geqslant 20.3 \mathrm{~mm}$ & $P_{\mathrm{s}}<20.3 \mathrm{~mm}$ \\
\hline 平均 $\delta^{18} \mathrm{O} / \% 0$ & 降水 & -6.54 & -6.77 & -4.72 \\
平均 $\Delta \delta^{18} \mathrm{O} / \% 0$ & 湖水 & 0 & -0.11 & 0.10 \\
平均 $d$-excess/\%0 & 降水 & 14.38 & 14.20 & 14.82 \\
平均 $\Delta d$-excess/\%0 & 湖水 & 0 & 0.48 & -0.47 \\
$\delta^{18} \mathrm{O}_{\mathrm{P}}-/ P_{\mathrm{s}}$ 斜率/截距 & 降水 & $-0.041 /-3.972$ & $-0.027 / /-4.915$ & $-0.151 /-2.863$ \\
$\Delta \delta^{18} \mathrm{O}_{\mathrm{L}}-P_{\mathrm{s}}$ 斜率/截距 & 湖水 & $-0.006 / 0.122$ & $-0.006 / 0.153$ & $-0.007 / 0.124$ \\
$\Delta d_{\mathrm{L}}-P_{\mathrm{s}}$ 斜率/截距 & & $0.014 /-0.402$ & $0.004 / 0.259$ & $0.082 /-0.875$ \\
$\Delta \delta^{18} \mathrm{O}_{\mathrm{L}}-E_{\mathrm{s}}$ 斜率/截距 & & $0.007 / 0.082$ & $0.006 /-0.178$ & $0.007 / 0.006$ \\
$\Delta d_{\mathrm{L}}-E_{\mathrm{s}}$ 斜率/截距 & & $-0.058 / 0.629$ & $-0.069 / 1.251$ & $-0.050 / 0.123$ \\
$\delta^{2} \mathrm{H}-\delta^{18} \mathrm{O}$ 斜率/截距 & & $8.30 / 15.89$ & $8.84 / 19.56$ & $8.19 / 15.34$ \\
& $\mathrm{LMWL}$ & $6.68 /-0.78$ & $6.86 / 0.68$ & $6.30 /-2.83$ \\
平均 5 日累计蒸发量 $E_{\mathrm{s}} / \mathrm{mm}$ & $\mathrm{LEL}$ & 11.72 & 11.54 & 12.11 \\
平均 5 日累计降水量 $P_{\mathrm{s}} / \mathrm{mm}$ & & 23.77 & 47.61 & 4.93 \\
平均 5 日湖水水位/m & & 29.79 & 29.86 & 29.74 \\
\hline
\end{tabular}

受重同位素蒸发富集的影响,湖水稳定同位素主要呈上升的趋势; 受偏负的降水同位素补给的影响,湖 水稳定同位素主要呈减小的趋势. 统计表明, 当 5 日累计降水量 $P_{\mathrm{s}} \geqslant 20.3 \mathrm{~mm}$ 时, 湖水稳定同位素变化量 $\Delta \delta^{18} \mathrm{O}_{\mathrm{L}}$ 与 $P_{\mathrm{s}}$ 之间的相关关系非常显著, 但与 5 日累计蒸发量 $E_{\mathrm{s}}$ 之间呈弱的相关性; 湖水中过量氞的变化量 $\Delta d_{\mathrm{L}}$ 与 $P_{\mathrm{s}}$ 之间无显著相关关系, 但与 $E_{\mathrm{s}}$ 之间呈弱的相关性; 相比于平均 LEL, 湖水蒸发线 LEL 的斜率和截距 均有明显增加. 这说明在强降水的作用下, 水体的蒸发富集作用被弱化. 当 $P_{\mathrm{s}}<20.3 \mathrm{~mm}$ 时, $\Delta \delta^{18} \mathrm{O}_{\mathrm{L}}$ 与 $P_{\mathrm{s}}$ 之间 的相关程度明显降低, 但与 $E_{\mathrm{s}}$ 之间的相关程度则明显提高; 湖水中 $\Delta d_{\mathrm{L}}$ 与 $P_{\mathrm{s}}$ 以及与 $E_{\mathrm{s}}$ 之间的相关关系显著 提高; 相比于平均 LEL, LEL 的斜率和截距均有明显减小. 这说明在弱降水的作用下,水体的重同位素蒸发 富集作用被加强.

可以看出, $P_{\mathrm{s}} \geqslant$ 和 $<$ 临界值 $20.3 \mathrm{~mm}$ 时, 湖水的稳定同位素变化特点具有显著的差异. 实际上, 当 $P_{\mathrm{s}} \geqslant$ $20.3 \mathrm{~mm}$ 时, 湖水的平均 $E_{\mathrm{s}}$ 为 $11.54 \mathrm{~mm}$; 当 $P_{\mathrm{s}}<20.3 \mathrm{~mm}$ 时, 湖水的 $E_{\mathrm{s}}$ 为 $12.11 \mathrm{~mm}$, 二者的差仅为 $0.57 \mathrm{~mm}$. 也就是说,两种条件下的湖水重同位素的蒸发富集率相差不大. 然而, 前者的平均 $P_{\mathrm{s}}(47.61 \mathrm{~mm})$ 几乎是后者 (4.93 mm) 的 10 倍. 在强降水条件下,降水对湖水稳定同位素的贫化作用远超蒸发对湖水稳定同位素的富 集作用; 在弱降水条件下,降水对湖水稳定同位素的贫化作用远低于蒸发对湖水稳定同位素的富集作用.

尽管受降水稳定同位素的贫化作用和湖水重同位素被蒸发富集作用的双重影响,但湖水重稳定同位素 
变化趋势与降水量和蒸发量之间并不具有相似性. 例如, 在降水量偏小或蒸发量偏大的季节, $\delta^{18} \mathrm{O}_{\mathrm{L}}$ 并非总是 呈上升的趋势; 在降水量偏大或蒸发量偏小的季节, $\delta^{18} \mathrm{O}_{\mathrm{L}}$ 也并非总是呈下降的趋势. 但是从 $\delta^{18} \mathrm{O}_{\mathrm{L}}$ 的变化细 节上还是可以发现强降水和强蒸发对湖水稳定同位素的影响. 例如,在 2015 年 10 月 6 日-11月 11 日期间 以及在 2016 年 7 月 16 日一 9 月 6 日期间, 由于降水量偏小 (累计降水量分别为 41.95 和 $100.3 \mathrm{~mm}$ )、蒸发量 偏强 (累计蒸发量分别为 95.3 和 $231.7 \mathrm{~mm}$ ), 平均水位低 (分别为 29.73 和 $29.85 \mathrm{~m}$ ), 湖水稳定同位素被明 显富集, $\delta^{18} \mathrm{O}_{\mathrm{L}}$ 分别由 $-4.02 \%$ 和 $-5.56 \%$ 增大到 $-3.47 \%$ 和 $-4.38 \%$; 又如, 在 2016 年 7 月 1 日一 7 月 6 日, 由于 强降水事件 (5 日累计降水量达到 $207.7 \mathrm{~mm}$ )、平均湖泊水位达到 $30.48 \mathrm{~m}$, 创观测期间的最高值. 受强降水 的影响, $\delta^{18} \mathrm{O}_{\mathrm{L}}$ 大幅度下降, 从 7 月 1 日的 $-3.69 \%$ 下跌到 7 月 6 日的 $-5.31 \%$, 创下了观测期间的最大跌幅. 这种现象并非个例, Steinman 等 ${ }^{[35]}$ 在调查华盛顿北部中央的两个小型封闭湖泊的稳定同位素组分时发现, 小型封闭的盆地湖泊对气候和水文胁迫的随机变化将表现出瞬态的稳定同位素响应.

虽然湖水的主要来源是降水, 但是 $\delta^{18} \mathrm{O}_{\mathrm{L}}$ 与 $\delta^{18} \mathrm{O}_{\mathrm{P}}$ 的关系并不密切, 二者的相关系数仅为 0.25 . 值得注意 的是, $\delta^{18} \mathrm{O}_{\mathrm{L}}$ 与同期浅层地下水 $\delta^{18} \mathrm{O}\left(\delta^{18} \mathrm{O}_{\mathrm{G}}\right)$ 之间的关系密切, 二者之间的拟合方程为: $\delta^{18} \mathrm{O}_{\mathrm{L}}=1.04 \delta^{18} \mathrm{O}_{\mathrm{G}}+$ $2.57(r=0.72, n=144)$ (图略), 两者的相关系数达到了 0.72 . 实际上, 浅层地下水也主要源于大气降水. 湖水 中和浅层地下水中稳定同位素的变化到底是降水稳定同位素变化的一因二果, 还是湖水稳定同位素受浅层 地下水补给的直接影响, 还有待于做深人的研究.

此外, 徐敬争等 ${ }^{[12]}$ 对与桃子湖属同一气候区的太湖进行了长期观测, 发现太湖湖水稳定同位素组分呈 现出夏季最高、冬季最低的季节变化特征, 同时他们并没有捕捉到湖水对强降水事件的响应信号,这与我们 的研究结果存在明显不同, 反映出在同一气候区域内,湖泊水对水文胁迫的稳定同位素响应的复杂性. 由于 我们数据的时间尺度为候, 相比于月数据、年数据, 我们可以提供更精细的湖水稳定同位素变化特征和更精 细的湖水同位素变化对环境气象要素的响应特征. 因此, 研究结果对认识湖泊的水文过程、湖水稳定同位素 的气候环境响应具有重要意义,同时也可为相关的水文学、古气候学等研究提供参考.

\section{5 参考文献}

[ 1 ] Zhang XP, Yao TD. Estimation of lake evaporation by stable isotopic ratio. Journal of Glaciology and Geocryology, 1997, 19(2) : 67-72. [章新平, 姚檀栋. 利用稳定同位素比率估计湖泊的蒸发. 冰川冻土, 1997, 19(2): 67-72.]

[ 2 ] Shaw GD, Mitchell KL, Gammons CH. Estimating groundwater inflow and leakage outflow for an intermontane lake with a structurally complex geology: Georgetown Lake in Montana, USA. Hydrogeology Journal, 2017, 25(1) : 135-149.

[ 3 ] Ma J, Edmunds WM. Groundwater and lake evolution in the Badain Jaran Desert ecosystem, Inne Mongolia. Hydrogeology Journal, 2006, 14(7): 1231-1243.

[ 4 ] Zhen ZL, Li CY, Li WB et al. Characteristics of environment isotopes of surface water and groundwater and their charge relationships in Lake Dali Basin. J Lake Sci, 2014, 26(6) : 916-922. DOI:10.18307/2014.0614. [ 甄志否, 李畅游, 李 文宝等. 内蒙古达里诺尔湖流域地表水和地下水环境同位素特征及补给关系. 湖泊科学, 2014, 26(6): 916-922.]

[ 5 ] Gat JR, Bowser CJ, Kendall C. The contribution of evaporation from the Great Lakes to the continental atmosphere: estimate based on stable isotope data. Geophysical Research Letters, 1994, 21(7) : 557-560.

[ 6 ] Wu JL, Liu JJ, Wang SM. Climatic change record from stable isotopes in Lake Aibi, Xinjiang during the past 1500 years. Quaternary Sciences, 2004, 24(5) : 585-590. [ 吴敬禄, 刘建军, 王苏民. 近 1500 年来新疆艾比湖同位素记录的气 候环境演化特征. 第四纪研究, 2004, 24(5): 585-590.]

[ 7 ] Jones MD, Cuthbert MO, Leng MJ et al. Comparisons of observed and modelled lake $\delta^{18} \mathrm{O}$ variability. Quaternary Science Reviews, 2016, 131 (part B) : 329-340.

[ 8 ] Mayr C, Lücke A, Stichler W et al. Precipitation origin and evaporation of lakes in semi-arid Patagonia ( Argentina) inferred from stable isotopes $\left(\delta^{18} \mathrm{O}, \delta^{2} \mathrm{H}\right)$. Journal of Hydrology, 2007, 334(1/2): 53-63.

[ 9 ] Talbot MR. A review of the palaeohydrological interpretation of carbon and oxygen isotopic ratios in primary lacustrine carbonates. Chemical Geology, 1990, 80(4) : 261-279.

[10] Leng MJ, Marshall JD. Palaeo climate interpretation of stable isotope data from lake sediment archives. Quaternary Science Reviews, 2004, 23(7/8): 811-831.

[11] Henderson AK, Shuman BN. Differing controls on river-and lake-water hydrogen and oxygen isotopic values in the western 
United States. Hydrological Processes, 2010, 24(26) : 3894-3906.

[12] Xu JZ, Xiao W, Xiao QT et al. Temporal dynamics of stable isotopic composition in Lake Taihu and controlling factors. Environmental Science, 2016, 37(7): 2470-2477. [徐敬争, 肖薇, 肖启涛等. 湖水氢氧同位素组分的时间变化特征 及影响因子分析. 环境科学, 2016, 37(7): 2470-2477.]

[13] Gong TL, Tian LD, Liu DN et al. A preliminary study of stable isotope cycle processes in lake water in the Yamzho lake basin. Journal of Glaciology and Geocryology, 2007, 29(6):914-920. [巩同梁, 田立德, 刘东年等. 羊卓雍湖流域湖 水稳定同位素循环过程研究. 冰川冻土, 2007, 29(6) : 914-920.]

[14] Biggs TW, Lai CT, Chandan P et al. Evaporative fractions and elevation effects on stable isotopes of high elevation lakes and streams in arid western Himalaya. Journal of Hydrology, 2015, 522 : 239-249.

[15] Jones MD, Roberts CN, Leng MJ. Quantifying climatic change through the last glacial-interglacial transition based on lake isotope palaeohydrology from central Turkey. Quaternary Science Reviews, 2007, 67(3) : 463-473.

[16] Zhang XP, Guan HD, Zhang XZ et al. Numerical tests on the impacts of surface evaporation and condensation fractionation on stable isotopes in precipitation: A comparison of temporal variation (taking the isotopes in precipitation at Changsha as an example). Journal of Glaciologyand Geocryology, 2017, 39(3) : 469-478. [章新平, 关华德, 张新主等. 下垫面蒸 发和云中凝结分馏对降水稳定同位素影响的数值试验——时间变化的比较 (以长沙降水同位素为例). 冰川冻土, $2017,39(3)$ : 469-478.]

[17] Zhang XP, Guan HD, Zhang XZ et al. Simulation of $\delta^{18} \mathrm{O}$ in atmospheric vapour and precipitation in Changsha Station, East Asian monsoon regions. Journal of Glaciology and Geocryology, 2015, 37(1): 249-257. [章新平, 关华德, 张新主 等. 季风区长沙站大气水汽和降水中 $\delta^{18} \mathrm{O}$ 的模拟. 冰川冻土, 2015, 37(1) : 249-257.]

[18] Ren ZH, Li MQ, Zhang WM. Conversion coefficient of small evaporation pan into E-601B pan in China. Quarterly Journal of Applied Meteorology, 2002, 13(4) : 508-514. [任芝花, 黎明琴, 张纬敏. 小型蒸发器对 E-601B 蒸发器的折算系 数. 应用气象学报, $2002,13(4): 508-514$. ]

[19] Liu J, Zhang Q, Xu CY et al. Change of actual evapotranspiration of Poyang Lake watershed and associated influencing factors in the past 50 years. Resources and Environment in the Yangtze Basin, 2010, 19(2): 139-145. [刘健, 张奇, 许 崇育等. 近 50 年鄱阳湖流域实际蒸发量的变化及影响因素. 长江流域资源与环境, 2010, 19(2):139-145.]

[20] Yao TC, Zhang XP, Xie YL et al. Variations of hydrogen and oxygen isotopes in atmospheric water vapor of near surface in Changsha. Acta Scientiae Circumstantiae, 2017, 37(2) : 545-553. [姚天次, 章新平, 谢宇龙等. 长沙地区近地面水汽 中氢氧稳定同位素的变化特征. 环境科学学报, 2017, 37(2):545-553.]

[21] Shi XY, Pu T, He YQ et al. Spatial distribution of stable isotope from the lakes in typical temperate glacier region. Environmental Science, 2016, 37(5) : 1685-1691. [史晓宜, 蒲春, 何元庆等. 典型温冰川区湖泊的稳定同位素空间分布 特征. 环境科学, 2016, 37(5): 1685-1691.]

[22] Li YL, Yao J, Zhang XL et al. Study on the vertical stratification in Poyang Lake. Resources and Environment in the Yangtze Basin, 2017, 26(6) : 915-924. [李云良, 姚静, 张小琳等. 鄱阳湖水体垂向分层状况调查研究. 长江流域资源 与环境, $2017,26(6): 915-924$. ]

[23] Gibson JJ, Edwards TWD, Birks SJ et al. Progress in isotope tracer hydrology in Canada. Hydrological Processes, 2005,19 (1) : 303-327.

[24] Liu ZF, Tian LD, Yao TD et al. Estimation of evaporation from Cona Lake in the central Tibetan Plateau using an isotopebased method. Journal of Natural Resources, 2009, 24(11): 2014-2023. [刘忠方, 田立德, 姚檀栋等. 基于 $\delta^{18} \mathrm{O}$ 的青 藏高原中部错那湖湖水蒸发研究. 自然资源学报, 2009, 24(11) : 2014-2023.

[25] Hu HY, Bao WM, Wang T et al. Application of isotopic technology in hydrology of lakes. Water Resources and Power, 2008, 26 (1) : 40-42. [ 胡海英, 包为民, 王涛等. 同位素技术在湖泊水文学中的应用研究. 水电能源科学, 2008, 26(1): 40-42.]

[26] Liu J, Song X, Yuan G et al. Stable isotopes of summer monsoonal precipitation in southern China and the moisture sources evidence from $\delta^{18} \mathrm{O}$ signature. Journal of Geographical Sciences, 2008, 18(2) : 155-165.

[27] Feng X, Faiia AM, Posmentier ES. Seasonality of isotopes in precipitation: A global perspective. Journal of Geophysical Research: Atmospheres, 2009, 114(D08): 1-13.

[28] Craig H. Isotopic variations in meteoric water. Science, 1961, 133(3465) : 1702-1703.

[29] Gibson JJ, Edwards TWD, Bursey GG. Estimating evaporation using stable isotopes: Quantitative results and sensitivity a- 
nalysis for two catchments in Northern Canada. Nordic Hydrology, 1993, 24(2/3) : 79-94.

[30] Tian LD, Yao TD, Sun WZ. The relationship between $\delta^{18} \mathrm{O}$ and $\delta \mathrm{D}$ in precipitation and the water vapor cycle in Tibetan Plateau. Science in China: Series D, 2001, 31(3) : 214-220. [田立德, 姚檀栋, 孙维贞. 青藏高原南北降水中 $\delta$ D 和 $\delta^{18} \mathrm{O}$ 关系及水汽循环. 中国科学: D 辑, 2001, 31(3): 214-220.]

[31] Zhan LC, Chen JS, Zhang SY et al. Characteristics of stable isotopes in precipitation, surface water and groundwater in the Dongting Lake region. Advances in Water Science, 2014, 25(3): 327-335. [詹泸成, 陈建生, 张时音. 洞庭湖湖区降 水-地表水-地下水同位素特征. 水科学进展, 2014, 25(3): 327-335.]

[32] Gibson JJ, Birks SJ, Yi Y. Stable isotope mass balance of lakes: A contemporary perspective. Quaternary Science Reviews, 2016, 131: 316-328.

[33] Zhang M, Wang S. A review of precipitation isotope studies in China: Basic pattern and hydrological process. Journal of Geographical Sciences, 2016, 26(7): 921-938.

[34] Yao TC, Zhang XP, Li G et al. Characteristics of the stable isotopes in different water bodies and their relationships in surrounding areas of Yuelu Mountain in the Xiangjiang River Basin. Journal of Natural Resources, 2016, 31(7) : 1198-1221. [姚天次, 章新平, 李广等. 湘江流域岳麓山周边地区不同水体中氢氧稳定同位素特征及相互关系. 自然资源学 报, 2016, 31(7): 1198-1221.]

[35] Steinman BA, Rosenmeier MB, Abbott M et al. The isotopic and hydrologic response of small, closed-basin lakes to climate forcing from predictive models: application to paleoclimate studies in the upper Columbia River basin. Limnology and Oceanography, 2010, 55(6) : 2231-2245. 